Theor Appl Genet (1989) 77:17-25

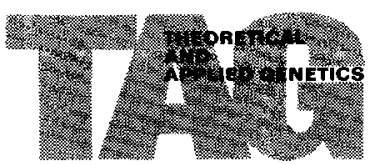

(C) Springer-Verlag 1989

\title{
Rearrangement, amplification, and assortment of mitochondrial DNA molecules in cultured cells of Brassica campestris
}

\author{
M. Shirzadegan ${ }^{1}$, M. Christey $^{2}$, E. D. Earle ${ }^{2}$ and J.D. Palmer ${ }^{1}$ \\ 1 Department of Biology, University of Michigan, Ann Arbor, MI 48109, USA \\ 2 Department of Plant Breeding, Cornell University, Ithaca, NY 14853-1902, USA
}

Received May 5, 1988; Accepted June 29, 1988

Communicated by P. Maliga

Summary. We compared Brassica campestris mitochondrial and chloroplast DNAs from whole plants and from a 2-year-old cell culture. No differences were observed in the chloroplast DNAs (cpDNAs), whereas the culture mitochondrial DNA (mtDNA) was extensively altered. Hybridization analysis revealed that the alterations are due entirely to rearrangement. At least two inversions and one large duplication are found in the culture mtDNA. The duplication element is shown to have the usual properties of a plant mtDNA high frequency "recombination repeat". The culture mtDNA exists as a complex heterogeneous population of rearranged and unrearranged molecules. Some of the culture-associated rearranged molecules are present in low levels in native plant tissue and appear to have sorted out and amplified in the culture. Other mtDNA rearrangements may have occurred de novo. In addition to alterations of the main mitochondrial genome, an $11.3 \mathrm{~kb}$ linear mtDNA plasmid present in whole plants is absent from the culture. Contrary to findings in cultured cells of other plants, small circular mtDNA molecules were not detected in the $B$. campestris cell culture.

Key words: Brassica - Callus culture - Mitochondrial DNA - Genomic variability

\section{Introduction}

Most plant mitochondrial DNAs (mtDNAs) examined so far exist as a heterogeneous population of circular molecules, which interconvert via recombination across direct repeats (Lonsdale et al. 1984; Palmer and Shields 1984).

Offprint requests to $M$. Shirzadegan
Despite its heterogeneity and large size, the mitochondrial genome of higher plants appears to be stable with extremely low levels of intraspecific variability (Oro et al. 1985; Palmer 1988). Tissue culture manipulations, however, can promote extensive alterations in plant mtDNAs. Restriction fragment analysis of mtDNA from a variety of plant systems, including tobacco (Dale et al. 1981), wheat (Hartmann et al. 1987), and Vicia faba (Negruk et al. 1986), has revealed quantitative differences in the stoichiometry of restriction fragments in mtDNA from whole plant and cell culture. Transposition of specific DNA fragments (Chourey and Kemble 1982), the complete loss of a subgenomic molecule (Rode et al. 1987), as well as the appearance of novel mtDNA types in somatic hybrids (Belliard et al. 1979; Kemble et al. 1986 a; Ozias-Akins et al. 1987) are further evidence for rapid mtDNA alteration in vitro. However, mtDNA alteration does not always occur following tissue culture. In several cases, upon visual inspection of restriction fragment patterns, no variation could be detected in the mtDNA of cultured cells compared to whole plants (Galun et al. 1982; Hanson 1984; Kool et al. 1985). McNay etal. (1984) suggested that the intensity of mtDNA rearrangement depends on the species, morphology, and age of the cultures.

The small size $(218 \mathrm{~kb})$ of the mitochondrial genome in Brassica campestris, together with the availability of detailed clone banks and physical maps (Palmer and Shields 1984), make this a highly suitable species for studying the nature and dynamics of mtDNA rearrangements in cultured plant cells. In this report, we show that the mitochondrial genome of $B$. campestris has become drastically altered in organization after 2 years of in vitro cell culture. Hybridization experiments with probes covering $96 \%$ of the genome were used to deduce the nature and extent of culture-associated mtDNA rear- 
rangements. In addition, our data provide evidence for the pre-existence in whole plants of rearranged forms of the genome that have been amplified to high copy number in cultured cells.

\section{Materials and methods}

The $B$. campestris L. cell culture was established from hypocotyl tissue of a rapid cycling, self-compatible line (CrGc no. 66, Crucifer Genetics Cooperative) in September, 1984 (Lentini et al. 1986). The hypocotyl explants $(1-2 \mathrm{~cm}$ long) were cultured horizontally on callus induction medium (Linsmaier and Skoog 1965) containing $5.0 \mathrm{mg} / 1$ benzylaminopurine(BP) and $5.0 \mathrm{mg} / 1$ naphthaleneacetic acid (NAA). Friable callus was maintained on Linsmaier and Skoog salts $+3 \%$ sucrose, $1.0 \mathrm{mg} / 1 \mathrm{NAA}$, $5.0 \mathrm{mg} / 1 \mathrm{BA}, 0.1 \mathrm{mg} / 1$ 2.4-dichlorophenoxyacetic acid (2,4-D), and $200 \mathrm{mg} / 1$ enzymatic casein hydrolysate (M medium). Cell suspensions were obtained from hypocotyl calli maintained for 3-5 months. Callus culture was derived from this suspension by plating cells onto solid media in August 1986 and was subcultured every 3 weeks.

In January 1987, mtDNAs were isolated from B. campestris tissue culture and whole plant by the DNAase-I procedure of Kolodner and Tewari (1972). Two sources of seed were used: the turnip variety 'Torch' and the rapid cycling line $\mathrm{CrGc}$ no. 66, from which the tissue culture was established. Whole plant mtDNAs were prepared from green leaves of 1-2 month-old plants. MtDNA restriction profiles and hybridization patterns were identical for the two plant lines with every restriction enzyme or probe used. Chloroplast DNA (cpDNA) was isolated using the procedure described by Kolodner and Tewari (1975). Plasmids containing $B$. campestris mtDNA PstI and SalI fragments are from the library described by Palmer and Shields (1984). Plasmid DNAs were isolated by the procedure of Birnboim and Doly (1979).

After electrophoresis on $0.7 \%$ agarose gels, DNAs were transferred bidirectionally to Zetabind nylon filters (AMF Cuono). The labelling of recombinant plasmids by nick-translation and filter hybridizations was performed as previously described by Palmer (1986). Filters were washed in $2 \times \mathrm{SSC}(0.3 \mathrm{M} \mathrm{NaCl} /$ $30 \mathrm{~m} M$ trisodium citrate) and $0.5 \%$ SDS at $65^{\circ} \mathrm{C}$ prior to autoradiography.

\section{Results}

\section{Extrachromosomal mitochondrial DNA molecules}

In cultured cells of several plant species examined in previous studies, mtDNA has been shown to exist as a heterogeneous population of predominantly small circular DNA molecules (see, for example, Bailey-Serres et al. 1987). However, such molecules were not observed in mtDNA isolated from the 2-year-old $B$. campestris cell culture line used for this investigation, nor in whole plant mtDNA. Minicircular DNAs were not detected either as a supercoiled fraction in $\mathrm{CsCl}$-ethidium bromide density gradients or as discrete, low molecular weight bands in ethidium bromide-stained agarose gels of undigested mtDNA (Fig. 1). Hybridization of mtDNA clones covering the mitochondrial genome to filters containing undigested mtDNA also failed to reveal small mtDNA mo-

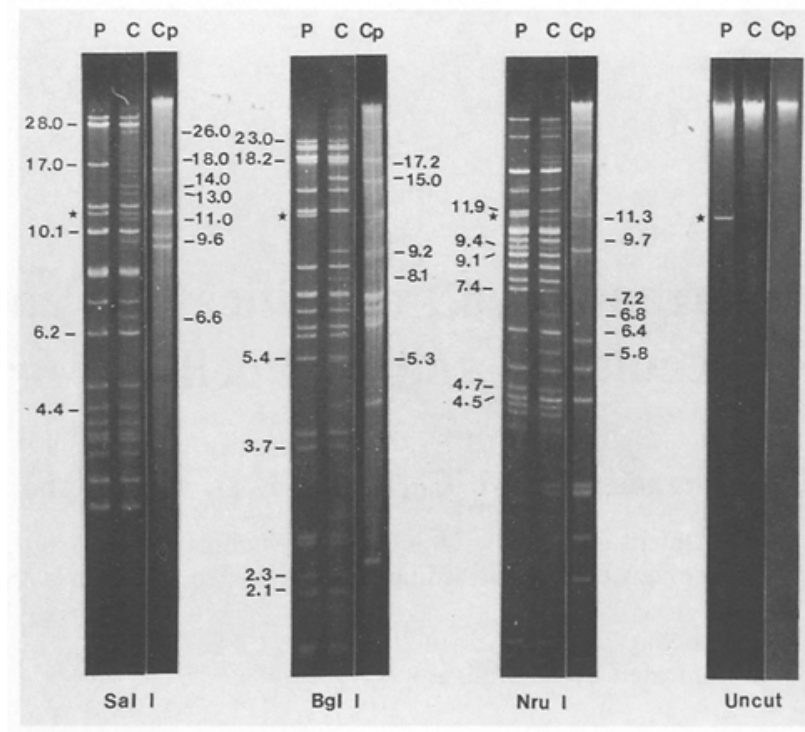

Fig. 1. Agarose gel electrophoresis of chloroplast DNA $(C p)$ and mtDNA from whole plant $(P)$ and cultured cells $(C)$ of B. campestris. Numbers to the left of gel lanes indicate the size of the whole plant fragments that are diminished or increased in intensity in the cultured cells. Numbers to the right of the lanes indicate novel fragments in cultured cells that are not visibly present in the $P$ or $C p$ lanes. Stars indicate an $11.3 \mathrm{~kb}$ linear plasmid-like DNA species in the whole plant mtDNA (Palmer et al. 1983)

lecules (data not shown). Furthermore, the $11.3 \mathrm{~kb}$ linear mtDNA plasmid previously noted in $B$, campestris plants (Palmer et al. 1983) is absent from mtDNA of cultured cells (Fig. 1). Hybridization experiments demonstrate that this molecule was originally present in the variety 'Torch' (P1) as well as the control parental line (P2), but has been eliminated during the 2 years of tissue culture (Fig. 2D).

\section{Comparison of $m t D N A$ restriction patterns}

MtDNAs from whole plants and cultured cells were compared with four restriction enzymes, PstI (not shown), Sall, BglI, and NruI (Fig. 1). The culture mtDNA was heavily contaminated with cpDNA. Therefore, purified cpDNA isolated from plant material was included in a lane next to the culture mtDNA in order to control for cpDNA contamination and allow detection of novel fragments arising from alterations of mtDNA. Hybridization with purified cpDNA to a filter blot of the gel shown in Fig. 1 reveals that this genome is unchanged in the culture compared to the native plant (data not shown).

Although restriction patterns of mtDNA from cultured cells and control plant display considerable overall similarity, several significant differences can be detected. These are of three types. First, NruI fragments of 11.9, $9.4,9.1,7.4$, and $4.7 \mathrm{~kb}$, as well as the corresponding 
fragments produced with SalI, BgII, and PstI, all appear submolar in the culture mtDNA relative to the whole plant. Second, and conversely, certain fragments (e.g., SalI 6.2, BglI 2.1, and NruI $4.5 \mathrm{~kb}$ ) are present in supermolar concentration in the culture line compared to native plants. Third, mtDNA from callus culture contains several novel fragments lacking in the mitochondrial genome of the intact plant (Fig. 1).

\section{Hybridization analysis of $m t D N A$ rearrangements}

In order to determine the location and nature (i.e., point mutation, inversion, transposition, duplication, etc.) of mtDNA alterations in the culture, a clone bank containing $96 \%$ of the $B$. campestris mitochondrial genome was used to probe Southern blots of gels similar to the one illustrated in Fig. 1. Each of $37 \mathrm{mtDNA}$ clones was hybridized to digests with PstI, SalI, BglI, and NruI. Interpretation of the hybridization data is complicated by a series of factors. First, several faint bands are observed in equal intensity in mtDNA of both genomes (e.g., P2.9, Fig. 2B). Based on studies to be reported elsewhere, these bands reflect the presence of small dispersed repeats in the mitochondrial genome of B. campestris. Second, due to homologies between cpDNA and mtDNA, several clones tested here cross-hybridize to a number of nonparental bands resulting from cpDNA contamination of the culture mtDNA preparation (e.g. P2.0, Fig. 2A). Another source of artefactual variability is observed in PstI digests of plant mtDNA (e.g., P7.7, Fig. 2A). The additional small fragments designated with an " $x$ " appear to be caused by a "star activity" of PstI (Malyguin et al. 1980).

Although all cloned fragments formed hybrids with expected fragment size classes, indicating a general conservation of the mitochondrial genome of the callus culture, several fragments are found to be altered (Fig. 2). Note that each of these clones (i.e., S10.1, S4.4, P9.7, P12.2, $\mathrm{P} 4.4, \mathrm{~S} 6.2$, S1.1) hybridize strongly to the parental fragments as well as at least one extra fragment in the culture mtDNA. In the case of Sall fragments of $6.2 \mathrm{~kb}$ and $1.1 \mathrm{~kb}$, the extra fragments are the same size as the parental fragments and in fact result from duplication (see below). These results reveal that the mitochondrial genome of cultured cells is heterogeneous, containing both molecules that retain their original genomic organization and ones that have been altered.

Further analysis reveals that several independent rearrangements have occurred in the mitochondrial genome of this B. campestris cell culture (Fig. 3). We focus our attention on the two most clear-cut of these events. Cloned fragments S10.1 and P12.2, which in the native plant genome lie $63 \mathrm{~kb}$ apart (Fig. 4), hybridize to the same two novel bands (e.g., PstI fragments of $16.8 \mathrm{~kb}$ and $14.5 \mathrm{~kb}$ ) in the culture mtDNA (Fig. $3 \mathrm{~A}$ and $\mathrm{C}$ ). Note also that the two novel bands resulting from this rearrangement sum to the same size as the two parental fragments (e.g., NruI: $11.3 \mathrm{~kb}+9.7 \mathrm{~kb}=\mathbf{1 1 . 9} \mathrm{kb}+9.1 \mathrm{~kb}$ ). The simplest interpretation of these results is that a large inversion having end points in S10.1 and P12.2 is present in a subset of the culture mtDNA molecules (Fig. 4). Similarly, SalI and PstI fragments of $4.4 \mathrm{~kb}$ hybridize to a single common fragment (i.e., SalI 6.6, Bgll 15.0, and NruI 6.4) in the culture mtDNA (Fig. 3B and E). The detection of only one novel fragment homologous to these clones could be due to a transposition event. However, this is unlikely, since no consistent pattern of increase or decrease in fragment size can be observed. We feel that an inversion is more likely, and that the failure to see two novel fragments hybridizing to $\mathrm{S} 4.4$ and P4.4 results from two complicating factors. First, one of the endpoints of the putative inversion maps extremely near the site of the restriction enzymes used (i.e., PstI 10.2, SalI 4.4, BglI 3.7). Second, there is another independent rearrangement within the PstI fragment of $4.4 \mathrm{~kb}$ (Fig. 4).

Another complex alteration in the genomic organization of the cultured cells is evident upon hybridization of S6.2 and S1.1 to the Sall digests of plant and culture mtDNAs. An increase in the hybridization signals of the parental bands is detected in the mtDNA of cultured cells (Fig. 2D). Given that equal amounts of DNA are loaded in each track, we conclude that the Sall fragments of $6.2 \mathrm{~kb}$ and $1.1 \mathrm{~kb}$ are duplicated in the culture mtDNA. Further hybridization analysis with S6.2 and S1.1 (Fig. 5) reveals the appearance of two novel fragments (e.g., PstI fragments of 15.0 and $13.6 \mathrm{~kb}$ ) which were observed in the P4.4 hybridization (Fig. 3E). This suggests that the Sall 6.2-1.1 duplication might lie close to P4.4 or a rearranged region containing part of P4.4.

All large duplications in plant mtDNA have been shown to be involved in high frequency intragenomic recombinations (e.g., Palmer and Shields 1984 and Fig. 2A, probe P4.8). To examine whether the SalI 6.2-1.1 duplication is also engaged in intragenomic recombination, S6.2 and S1.1 were hybridized to Southern blots of culture mtDNA digested with SacII, HpaI, and BstEII. Although none of these enzymes cleaves within this region, four restriction fragments show homology to each clone (data not shown). In each case, the largest and smallest fragments sum in size to the two intermediate ones. Based on these observations, we feel that this culture-specific duplication is active in recombination and meets the definition (Stern and Palmer 1984) of a high frequency "recombination repeat".

An additional rearrangement is evident by the weak hybridization of P9.7 to PstI fragments of 28.0 and $15.0 \mathrm{~kb}$ (Fig. 2A). Although the exact nature of this rearrangement is unclear, there appears to be some physical 

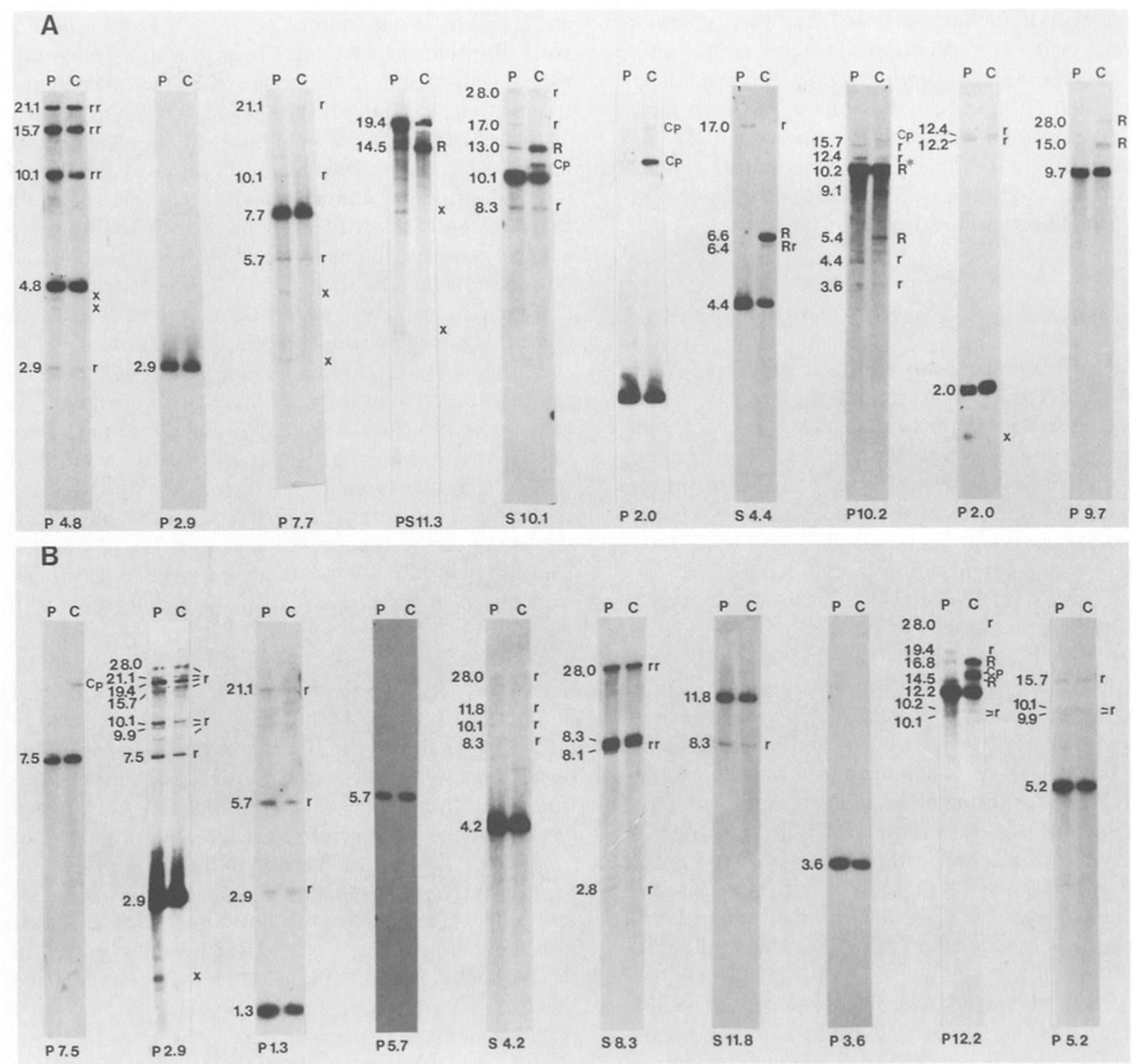

Fig. 2 A-D. Filter hybridization analysis of mtDNA variation. Total mtDNAs from whole plants $(P)$ and a 2-year-old callus culture $(C)$ were digested with PstI and SalI, separated on a $0.7 \%$ agarose gel, transferred bidirectionally to Zetabind filters, and hybridized with the indicated cloned fragments covering $96 \%$ of the mitochondrial genome of $B$. campestris. The clone designations indicate the type of fragment cloned ( $P$ for PstI and $S$ for SalI) and its size in kb. Sizes of mtDNA fragments (but not fragments resulting from cpDNA contamination) are indicated to the left of each filter strip, while novel fragments in the culture mtDNA are denoted to the right according to the following conventions. Fragments containing the $2 \mathrm{~kb}$ recombination repeats of $B$. campestris are designated as $r r$. Fragments resulting from cpDNA contamination are designated as $C p$. The extra bands $x$ noted only in PstI digests of the plant mtDNA result from putative "star activity" of this enzyme. Rearranged fragments of culture mtDNA are designated with an $R . R^{*}$ marks a $10.2 \mathrm{~kb}$ novel fragment that comigrates with a native fragment of the same size (panel $A$ ). Faint bands $(r)$ of equal intensity in both $P$ and $C$ lanes reflect the presence of small dispersed repeats. $R r$ designates hybridization to an altered mtDNA fragment that is mediated by these dispersed repeats. In panel $D$, the extrachromosomal plasmid described previously (Palmer et al. 1983) was hybridized to two sources of whole plant mtDNA: the variety 'Torch' $(P 1)$ and the rapid cycling line 84-141 (P2), from which the callus culture $(C)$ was established

linkage between P9.7, P4.4, and S6.2 (Fig. 2A, C, and 5). These clones all hybridize to a novel PstI fragment of $15.0 \mathrm{~kb}$, suggesting that a rearranged form of the genome contains sequences from all three clones in a single region.
One intriguing result is the detection in the whole plant mtDNA of minor hybridization signals to nonparental fragments that are characteristic of the culture mtDNA (e.g., Sall 14.0, and $13.0 \mathrm{~kb}$, Fig. 3C; BgII 9.2 and $8.1 \mathrm{~kb}$, Fig. 3D). This observation suggests that the 

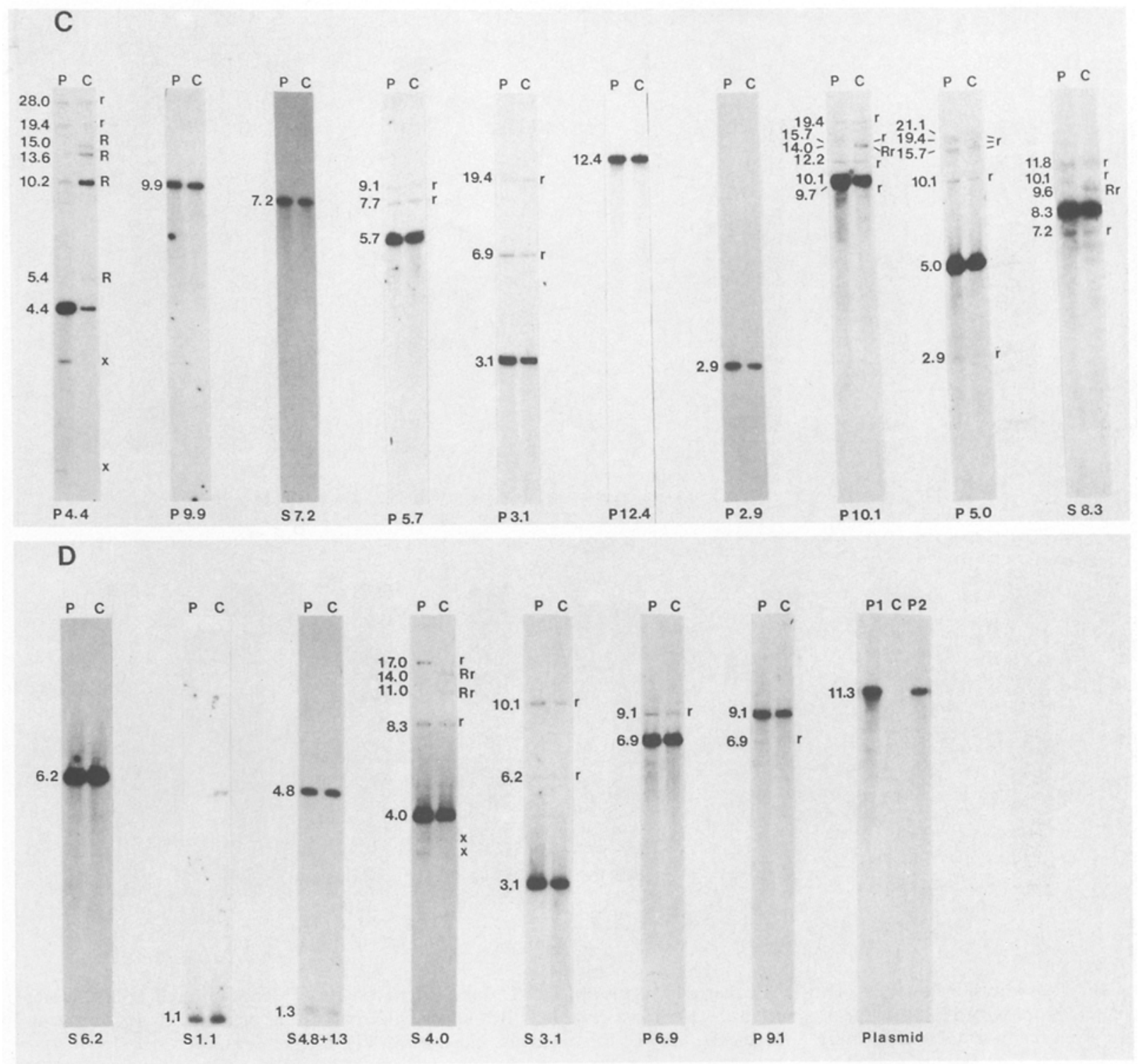

Fig. 2C, D

parental plant mtDNA contains low levels of at least some of the culture-associated rearrangements.

\section{Discussion}

The results of this investigation, combined with other observations reported previously (Gengenbach et al. 1981; Kemble et al. 1982; McNay et al. 1984; Hartmann et al. 1987), suggest that tissue culture increases the lability of the higher plant mitochondrial genome. Restriction pattern analysis, as well as molecular hybridization using a nearly complete mtDNA clone library, allowed us to detect several inversions and one duplication in the mitochondrial genome of $B$. campestris cell culture. Figure 4 summarizes a tentative outline of these events. We postulate that approximately four rearrangements have occurred in the culture mtDNA. One rearrangement is detected within PstI fragments of $19.4 \mathrm{~kb}$ (encompassing the cloned fragment S10.1) and $12.2 \mathrm{~kb}$. The endpoints of another inversion lie within the SalI and PstI fragments of $4.4 \mathrm{~kb}$. However, the variable intensity of the hybridization signals of S4.4 (approximately 50\%) and P4.4 $(90 \%)$ to their parental fragments indicates that a portion of the molecules (approximately $40 \%$ ) contain a second separate rearrangement involving the $\mathrm{P} 4.4$ region (see Fig. $3 \mathrm{~B}$ and E). Note that P4.4 contains a number of small repeated sequences (see SalI digestion in Fig. 3E), which could account for the multiple inversional events confined to this region. 


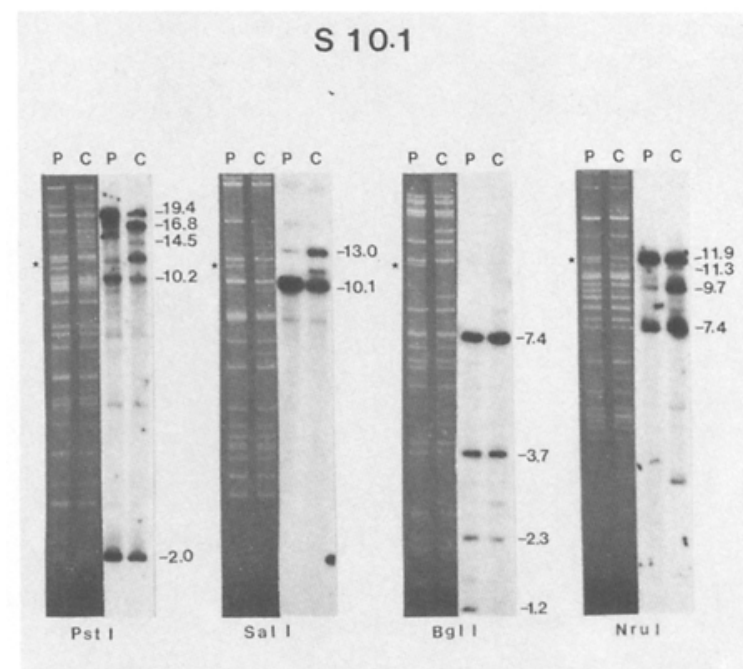

A

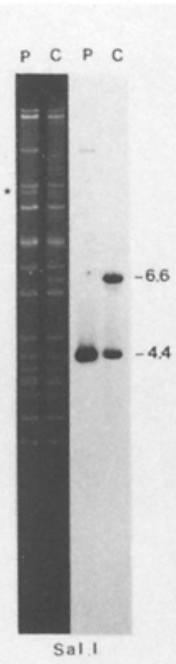

P 5.2

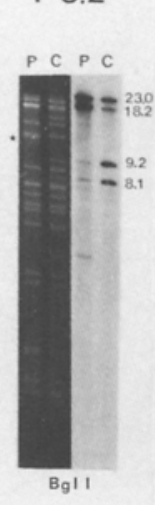

D
S 4.4

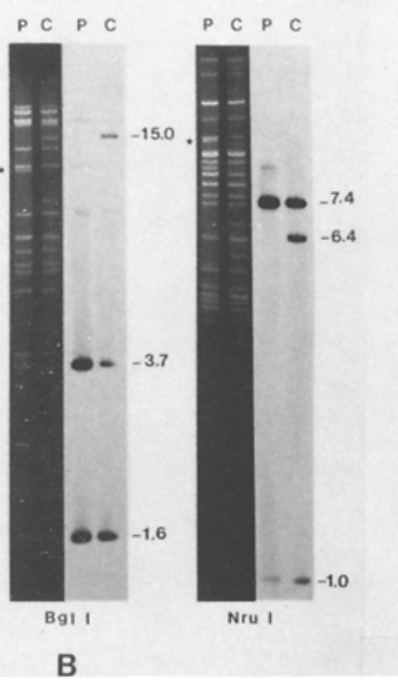

P 4.4

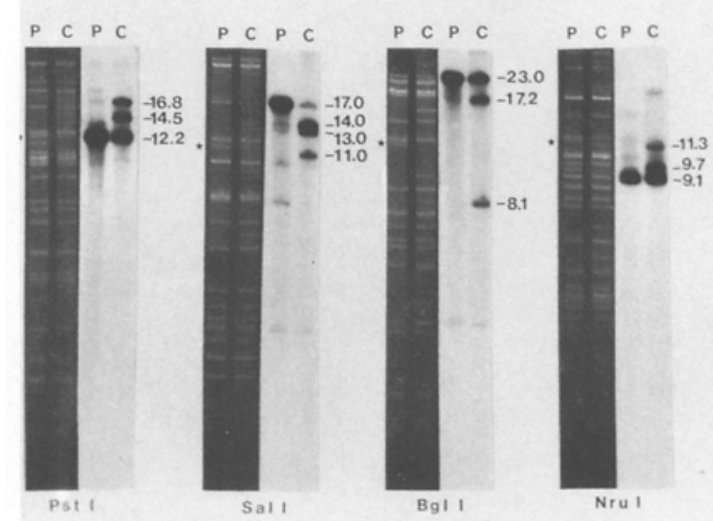

C

Fig. 3 A-E. Hybridization analysis of mtDNA rearrangements. MtDNAs from whole plants $(P)$ and cultured cells $(C)$ were restricted, electrophoresed in a $0.7 \%$ agarose gel, transferred to a Zetabind filter, and hybridized with the indicated cloned fragments. Sizes are given for parental and rearranged fragments, but not for fragments indicated in Fig. 2 by $r, R r, C p$, or $x$

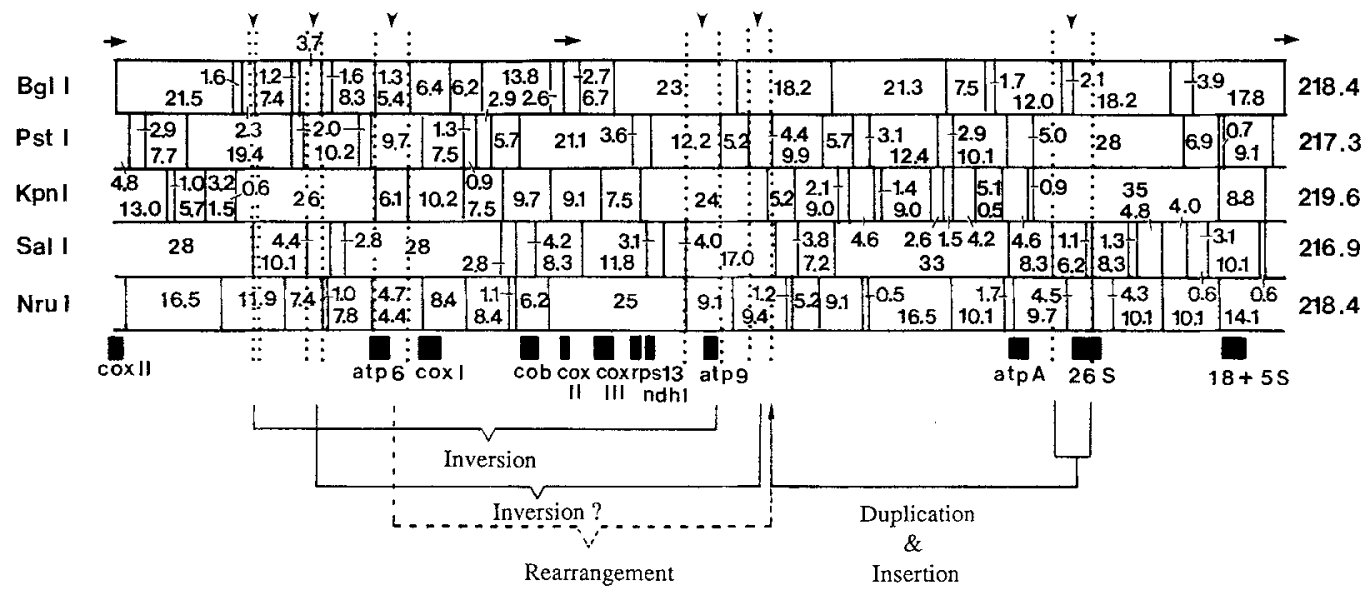

Fig. 4. Restriction site and gene map of the master chromosome of $B$. campestris mitochondrial DNA. The arrows indicate the location, as bounded by the dashed lines, of rearrangement endpoints in the mitochondrial genome of the cultured cells 


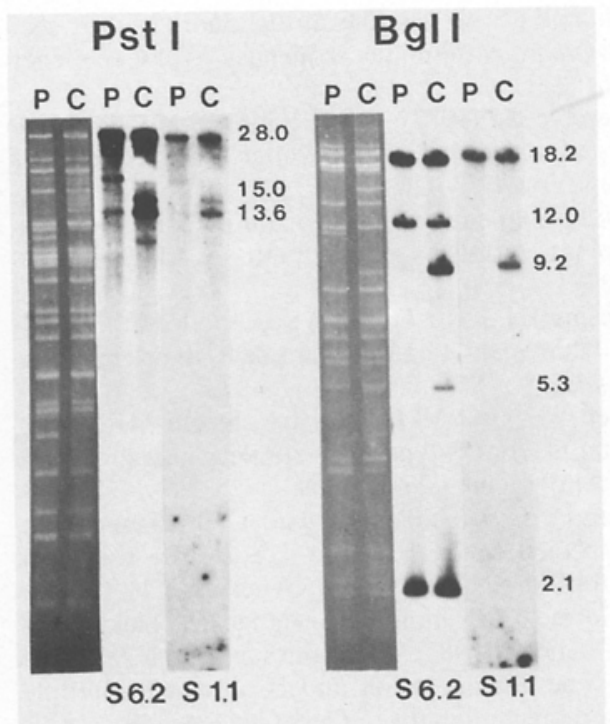

Fig. 5. Duplication of Sall fragments of $6.2 \mathrm{~kb}$ and $1.1 \mathrm{~kb}$ in mtDNA of cultured cells. The indicated restriction fragments from plant $(P)$ and culture $(C)$ were separated on a $0.7 \%$ agarose gel, blotted, and hybridized with the indicated clones

Sall fragments of $6.2 \mathrm{~kb}$ and $1.1 \mathrm{~kb}$, which contain part of the only 26S rRNA gene in Brassica, are duplicated in culture mtDNA. This gene is also present in multiple copies in mtDNAs of wheat, spinach, and pokeweed (Stern and Palmer 1984; Falconet et al. 1985). The presence of large duplications in the plant mitochondrial genome has been shown to be associated with high frequency intragenomic recombinations (Stern and Palmer 1984). Our results suggest that the SalI 6.2-1.1 duplication in culture mtDNA has the usual properties of a plant mtDNA "recombination repeat" and is active in intragenomic recombination.

The minor hybridization signals of $\mathrm{P} 9.7$ to two nonparental PstI fragments of 28.0 and $15.0 \mathrm{~kb}$ reveal the occurrence of a fourth rearrangement in the culture mtDNA. However, due to the apparent complexity of the alterations occurring in the $B$. campestris culture mtDNA, the exact nature of this rearrangement could not be assessed.

A comparison between the location of the cultureassociated rearrangements reported here (Fig. 4) and the three evolutionary inversions distinguishing the mitochondrial genomes of $B$. campestris and $B$. oleracea (Palmer and Herbon 1988) reveals that three of the postulated endpoints of the evolutionary inversions fall within the same fragments also affected by alteration of the culture mtDNA (i.e., S10.1, P12.2, P4.4). This comparison suggests that certain regions of the $B$. campestris mitochondrial genome are more susceptible to change and tend to promote inversional recombination and restructuring of the genome. Since intramolecular recombi- nation might be linked to the prevalence of short, dispersed repeats (Bowman and Dyer 1986), sequencing studies are currently in progress to clarify the relationship between short repeats and inversional events in the mitochondrial genome of $B$. campestris.

The fact that each cloned fragment corresponding to an altered region also hybridizes to a parental fragment (Figs. 2 and 3 ) indicates that the mitochondrial genome of cultured cells is a mixed population of rearranged and unrearranged molecules. MtDNA heterogeneity could occur within each individual cell or within a given cell population. The existence of a heterogeneous population of mtDNA molecules has been reported within tissues of individual dairy cows (Hauswirth et al. 1984). A comparison of the restriction patterns of mtDNA from callus clones derived from protoplasts will enable us to determine whether the heterogeneity of the culture mtDNA is a characteristic of each individual cell or perhaps reflects the existing variation within the cell population.

In contrast to findings with many other plant cultures where small circular mtDNA molecules are quite abundant (Synenki et al. 1978; Sparks and Dale 1980; Brennicke and Blanz 1982; Negruk et al. 1986; Bailey-Serres et al. 1987), no small circular DNA molecules are detected in the mitochondrial genome of the $B$. campestris culture examined here. Hause et al. (1986) also failed to observe such minicircles in the mitochondrial genome of Lycopersicon esculentum. This may have resulted from the nicking of closed circular molecules during mtDNA isolation. Another plausible explanation is that the variable abundance of supercoiled fraction in the mtDNA preparations of different cultures reflects the situation in vivo. Greyburn and Bendich (1987) applied the same mtDNA extraction technique described by Sparks and Dale (1980) to two different cultivars of Nicotiana tabacum; however, no supercoiled mtDNA molecules were obtained from suspension cultures of one cultivar (Turkish samsun).

Another change in the mtDNA of cultured cells examined here is the disappearance of the $11.3 \mathrm{~kb}$ plasmidlike molecule previously reported in B. campestris (Palmer et al. 1983). The loss and possible transposition of $\mathrm{S} 1$ and $\mathrm{S} 2$ plasmid-like molecules have also been reported in callus cultures derived from the $\mathrm{S}$ type male-sterile maize (Chourey and Kemble 1982; Earl et al. 1987). No close association exists between the presence of this extrachromosomal molecule and cytoplasmic male sterility in Brassica (Erickson et al. 1986). Furthermore, the plasmid lacks any significant homology to both chloroplast and mitochondrial genomes (Kemble et al. 1986 b). Whether any functional importance can be attributed to the loss or gain of this molecule is questionable; our studies, however, do indicate that this molecule is highly unstable.

Unlike the restriction patterns of mtDNA, those of the chloroplast genome have remained unchanged dur- 
ing 2 years of in vitro culture. This observation illustrates the high stability and low apparent rate of structural rearrangement of cpDNA reported in whole plants (Timothy et al. 1979; Palmer and Zamir 1982; Kung et al. 1982; Palmer and Stein 1986) and in cell cultures (Seyer et al. 1982; Kemble et al. 1986 a).

An intriguing outcome of our study is the detection of minor hybridization signals to novel fragments also visible in the mtDNA sample of control plants. This observation suggests that at least some of the culture-derived modified molecules are already present in the plant, but in much lower abundance $(1 \%-5 \%)$. Trivial factors or accidental results (e.g., contamination from adjacent lanes or carry-over from re-using a filter) that could produce similarities in the hybridization patterns of cell culture and whole plant have been ruled out. One possible explanation for this observation could be that the seed stock of B. campestris used to initiate the cell suspension/ callus culture contained a mixture of cytoplasms with rearranged and unrearranged genomes. However, plant mtDNA utilized throughout this investigation is isolated from an unrelated cultivar (i.e., 'Torch'). Therefore, this possibility is rather unlikely to account for the presence of low levels of some of the rearranged molecules noted also in the mitochondrial genome of the control plants. Sub-stoichiometric molecules characteristic of male sterile cytoplasms are also observed in the mtDNA of male fertile maize plants probed with atp A-specific sequences (Small et al. 1987). Our data are in accordance with theirs, suggesting that the products of recombination events may be retained in the mitochondrial genome for many generations at low levels. Exceptional circumstances (e.g., in vitro culture) might lead to amplification and assortment of subliminal molecules already present in the plant tissue.

Acknowledgments. We thank T. Deussen for assistance in typing and editing the manuscript and $J$. Nugent, P. Calie, and C. Makaroff for critical reading of the manuscript. This research was supported by NIH grant GM-35087 to J.D.P, USDA grant 85-00363 to E.D. Earle, and a NRAC postgraduate fellowship from the New Zealand government to M. Christey.

\section{References}

Bailey-Serres J, Leroy P, Jones SS, Wahleithner JA, Wolstenholme DR (1987) Size distributions of circular molecules in plant mitochondrial DNAs. Curr Genet 12:49-53

Belliard G, Vedel F, Pelletier G (1979) Mitochondrial recombination in cytoplasmic hybrids of Nicotiana tabacum by protoplast fusion. Nature 281:401-403

Birnboim HL, Doly J (1979) A rapid alkaline extraction procedure for screening recombinant plasmid DNA. Nucleic Acids Res 7:1513-1523

Bowman CM, Dyer TA (1986) The location and possible evolutionary significance of small dispersed repeats in wheat ctDNA.Curr Genet 10:931-941
Brennicke A, Blanz P (1982) Circular mitochondrial DNA species from Oenothera with unique sequences. Mol Gen Genet 187:461-466

Chourey PS, Kemble RJ (1982) Transposition events in tissue cultured cells of maize. In: 5th Int Congr Plant Tissue Cell Culture (Tokyo) pp 425-426

Dale RMK (1981) Sequence homology among different size classes of plant mtDNAs. Proc Natl Acad Sci USA 78: $4453-4457$

Dale RMK, Duesing JH, Keen D (1981) Supercoiled mitochondrial DNAs from plant tissue culture cells. Nucleic Acids Res 9:4583-4593

Earle ED, Gracen VE, Best VM, Batts LA, Smith ME (1987) Fertile revertants from S-type male-sterile maize grown in vitro. Theor Appl Genet 74:601 -609

Erickson L, Grant I, Beversdorf W (1986) Cytoplasmic male sterility in rapeseed (Brassica napus L.). 2. The role of a mitochondrial plasmid. Theor Appl Genet 72:151-157

Falconet D, Delorme S, Lejeune B, Sévignac M, Delcher E, Bazetoux S, Quétier F (1985) Wheat mitochondrial 23S ribosomal RNA gene has no intron and is present in mutiple copies arising by recombination. Curr Genet 9:169-174

Galun E, Arzee-Gonen P, Fluhr R, Edelman M, Aviv D (1982) Cytoplasmic hybridization in Nicotiana: mitochondrial DNA analysis in progenies resulting from fusion between protoplasts having different organelle constitutions. Mol Gen Genet 186:150-156

Gengenbach BG, Connelly JA, Pring DR, Conde MF (1981) Mitochondrial DNA variation in maize plants regenerated during tissue culture selection. Theor Appl Genet 59:161-167

Greyburn WS, Bendich AJ (1987) Variable abundance of a mitochondrial DNA fragment in cultured tobacco cells. Curr Genet 12:257-261

Hanson MR (1984) Stability, variation, and recombination in plant mitochondrial genomes via tissue culture and somatic hybridisation. Oxford Surv Plant Mol Cell Biol 1:33-52

Hartmann C, de Buyser J, Henry Y, Falconet D, Lejeune B, Benslimane A, Quétier F, Rode A (1987) Time-course of mitochondrial genome variation in wheat embryogenic somatic tissue cultures. Plant Sci 53:191-198

Hause B, Baldauf F, Stock K, Wasternack C, Metzlaff M (1986) Molecular analysis of mitochondrial DNA from tomato cell suspension cultures. Curr Genet 10:785-790

Hauswirth WW, Van de Walle MJ, Laipis PJ, Olivo PD (1984) Heterogeneous mitochondrial DNA D-loop sequences in bovine tissue. Cell 37:1001-1007

Kemble RJ, Flavell RB, Brettell RIS (1982) Mitochondrial DNA analysis of fertile and sterile maize plants derived from tissue culture with the Texas male sterile cytoplasm. Theor Appl Genet 62:213-217

Kemble RJ, Barsby TL, Wong RSC, Shepard JF (1986a) Mitochondrial DNA rearrangements in somatic hybrids of Solanum tuberosum and Solanum brevidens. Theor Appl Genet 72:787-793

Kemble RJ, Carlson JE, Erickson LR, Sernyk JL, Thompson DJ (1986 b) The Brassica mitochondrial DNA plasmid and large RNAs are not exclusively associated with cytoplasmic male sterility. Mol Gen Genet 205:183-185

Kolodner R, Tewari KK (1972) Physiochemical characterization of mitochondrial DNA from pea leaves. Proc Natl Acad Sci USA 69:1830-1834

Kolodner R, Tewari KK (1975) The molecular size and conformation of chloroplast DNA from higher plants. Biochem Biophys Acta 402:372-390

Kool AJ, deHaas JM, Mol JNM, van Marrewijk GAM (1985) Isolation and physiochemical characterization of mitochon- 
drial DNA from cultured cells of Petunia hybrida. Theor Appl Genet 69:223-233

Kung SD, Zhu YS, Shen GF (1982) Nicotiana chloroplast genome. 3. Chloroplast DNA evolution. Theor Appl Genet $61: 73-79$

Lentini Z, Christey M, Earle ED, Mutchler MA (1986) Cell suspension culture of rapid-cycling Brassica campestris L. Cruciferae Newsl 11:87-87

Levings CS III, Shah DM, Hu WWL, Pring DR, Timothy DH (1979) Molecular heterogeneity among mitochondrial DNAs from different maize cytoplasms. In: Cumming DJ, Borst P, Dawid J, Weisman SMG, Fox CF (eds) Extrachromosomal DNA. Academic Press, New York, pp 3-73

Linsmaier EM, Skoog F (1965) Organic growth factor requirements of tobacco tissue cultures. Physiol Plant 18:100-127

Lonsdale DM, Hodge TP, Fauron CMR (1984) The physical map and organization of the mitochondrial genome from the fertile cytoplasm of maize. Nucleic Acids Res 12:9249-9261

McNay JW, Chourey PS, Pring DR(1984) Molecular analysis of genomic stability of mitochondrial DNA in tissue cultured cells of maize. Theor Appl Genet 67:433-437

Malyguine E, Vannier P, Yot P (1980) Alteration of the specificity of restriction endonucleases in the presence of organic solvents. Gene 8:163-177

Negruk VI, Eisner GI, Redichkina TD, Dumanskaya NN, Cherny DI, Alexandrov AA, Shemyakin MF, Butenko RG (1986) Diversity of Vicia faba circular mtDNA in whole plants and suspension cultures. Theor Appl Genet $72: 541-547$

Oro AE, Newton KJ, Walbot V (1985) Molecular analysis of the mitochondrial genome of an inbred line of maize. Theor Appl Genet 70:287-293

Ozias-Akins P, Pring DR, Vasil IK (1987) Rearrangement in the mitochondrial genome of somatic hybrid cell lines of Pennisetum americanum (L.) K. Schum. + Panicum maximum Jacq. Theor Appl Genet 74:15-20

Palmer JD (1986) Isolation and structural analysis of chloroplast DNA. Methods Enzymol 118:167-186

Palmer JD (1988) Intraspecific variation and multicircularity in Brassica mitochondrial DNAs. Genetics 118:341-351
Palmer JD, Herbon LA (1988) Plant mitochondrial DNA evolves rapidly in structure, but slowly in sequence. $\mathrm{J}$ Mol Evol (in press)

Palmer JD, Shields CR (1984) Tripartite structure of the Brassica campestris mitochondrial genome. Nature 307:437-440

Palmer JD, Stein DB (1986) Conservation of chloroplast genome structure among vascular plants. Curr Genet 10:823-833

Palmer JD, Zamir D (1982) Chloroplast DNA evolution and phylogenetic relationships in Lycopersicon. Proc Natl Acad Sci USA 79:5006-5010

Palmer JD, Shields CR, Cohen DB, Orton TJ (1983) An unusual mitochondrial DNA plasmid in the genus Brassica. Nature 301:725-728

Rode A, Hartmann C, Falconet D, Lejeune B, Quétier F, Benslimane A, Henry Y, de Buyser J (1987) Extensive mitochondrial DNA variation in somatic tissue cultures initiated from wheat immature embryos. Curr Genet 12:369-376

Seyer P, Herrmann RG, Lescure AM (1982) Purification of plastid DNA from tobacco cell suspensions. Plant Sci Lett 25:345-352

Small ID, Isaac PG, Leaver CJ (1987) Stoichiometric differences in DNA molecules containing atpA gene suggest mechanisms for the generation of mitochondrial genome diversity in maize. EMBO J 6:865-869

Sparks RBJ, Dale RMK (1980) Characterization of 3H-labeled supercoiled mitochondrial DNA from tobacco suspension culture cells. Mol Gen Genet 180:351-355

Stern DB, Palmer JD (1984) Recombination sequences in mitochondrial genomes: diversity and homologies to known mitochondrial genes. Nucleic Acids Res 12:6141-6157

Synenki RM, Levings CS III, Shah DM (1978) Physiochemical characterization of mitochondrial DNA from soybean. Plant Physiol 61:460-464

Timothy DH, Levings CS III, Pring DR, Conde MF, Kermicle JL (1979) Organelle DNA variation and systematic relationships in the genus Zea: Teosinte. Proc Natl Acad Sci USA $76: 4220-4224$ 